\title{
Orbital Adnexal Lymphoma Diagnostic Misalignment
}

\author{
Blerta Rama, Anita Syla Lokaj, Egzona Agusholli \\ Department of Ophthalmology, University Center Clinic of Kosova, Prishtina, Kosovo \\ Email: Blerta.rama@uni-pr.edu, Anitasylaj@live.com
}

How to cite this paper: Rama, B., Lokaj, A.S. and Agusholli, E. (2017) Orbital Adnexal Lymphoma Diagnostic Misalignment. Open Journal of Ophthalmology, 7, 303-309.

https://doi.org/10.4236/ojoph.2017.74039

Received: October 3, 2017

Accepted: November 6, 2017

Published: November 9, 2017

Copyright ( 92017 by authors and Scientific Research Publishing Inc. This work is licensed under the Creative Commons Attribution International License (CC BY 4.0).

http://creativecommons.org/licenses/by/4.0/

\begin{abstract}
Lymphomas are known as neoplasm's caused by clone proliferation of B and $\mathrm{T}$ lymphocytes. Extranodal lymphoma arises from tissues other than lymph nodes or even from sites which normally doesn't contain lymph tissues. Orbital adnexal lymphoma arises from eyelid, orbit, lacrimal glands or conjunctivae and it is totally different from intraocular lymphoma. Wide range of differential diagnosis including infectious inflammatory orbital disease, preseptal and orbital cellulitis, orbital idiopathic inflammatory disease-pseudotumors, especially dacryoadenitis and myositis and thyroid associate orbit disease makes the diagnosis of orbital adnexal lymphoma even more difficult. We represent the case of diagnostic delay of very aggressive form orbital nonHodgkin lymphoma occurred because of the unspecific signs and symptoms as well as not indicative imaging investigation and laboratory tests.
\end{abstract}

\section{Keywords}

Orbital Adnexal Lymphoma, Extranodal Orbital Lymphoma, NHL, OAL

\section{Introduction}

Lymphomas are known as neoplasm's caused by clone proliferation of $\mathrm{B}$ and $\mathrm{T}$ lymphocytes. Based on WHO Classification of Tumor of Hematopoietic and Lymphatic Tissues, there are 30 different subtypes [1]. There are 4 categories: Hodgkin and non-Hodgkin lymphoma, myeloma multiple and immunoproliferative disease, but $90 \%$ of patients have non-Hodgkin lymphoma [2]. Primary nodal lymphomas arise from lymph nodes and primary extranodal lymphomas arise from tissues other than lymph nodes or even from sites which normally doesn't contain lymph tissues [3].

Extranodal non-Hodgkin lymphomas appear more often in gastrointestine, skin, and but also in head and neck, nervous system and orbital lymphoma [4] 
[5]. Although intraocular and orbital adnexal NHL appears to be less than 5\% $15 \%$ of all NHL and less than $1 \%$ of all NHL, it is the most common orbital malignancy representing up to $55 \%$ of all orbital tumors [6].

Orbital adnexal lymphoma arises from eyelid, orbit, lacrimal glands or conjunctivae, totally different from intraocular lymphoma [7]. In non-Hodgkin orbital lymphoma, MALT tumors are more common than DLBCL [8].

Sign and symptoms can vary depending on the site of the orbit. Usually they are presented as an orbital palpebral mass, initially painless proptosis, with or without motility limitations, tearing and chemosis. Depending on lymphoma localization, especially when it arises in the posterior orbit or it has muscular involvement, visual impairment, optic nerve compression and motility limitations can manifest [9] [10].

Differential diagnosis includes infectious inflammatory orbital disease, preseptal and orbital cellulitis, orbital idiopathic inflammatory disease-pseudotumors, especially dacryoadenitis and myositis and thyroid associate orbit disease. They make the diagnosis much more difficult [11] [12].

The diagnosis is based on clinical and ophthalmology examinations, laboratory test, blood test, liver and kidney functions tests, chest $\mathrm{x}$-ray, imaging investigation: computed topography (CT) and magnetic resonance imaging (MRI). It is important to evaluate medical history and systemic examination of possible lymphatic involvement. Biopsy represents very important diagnostic key.

We represent the case of diagnostic delay of very aggressive form orbital non-Hodgkin lymphoma occurred because of the unspecific signs and symptoms as well as not indicative imaging investigation and laboratory tests. The purpose is to emphasize the importance of the early biopsy for the better and faster therapeutic and prognostic results.

\section{Case Report}

We represent the case study of unilateral non Hodgkin lymphoma. A 48 years old male patient was presented in our clinic with proptosis of the left eye and with palebral ptosis. Before coming in the clinic he was treated in the ambulances with antibiotics, but with no improvement (Figure 1).

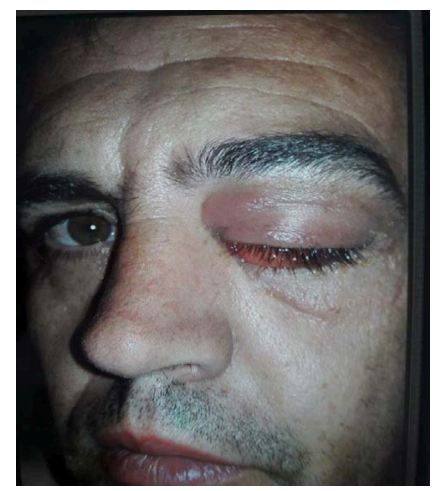

Figure 1. Patient before the admitting in hospital. 
(Photo from patient). On clinical examination his visual acuity was normal, 1.0 in both eyes, with normal intraocular pressure $15.0 \mathrm{mmHg}$ of the right and Ndig left eye, fundus examination with normal limits and negative afferent pupillary defect. He had painless proptosis, palpebral ptosis, little motility disturbance and conjuctival chemosis of the left eye (Figure 2). Working as a guardian, he was only diagnosed with HTA using therapy and had negative medical history other diseases. He had no signs and symptoms for any kind of systemic inclusion.

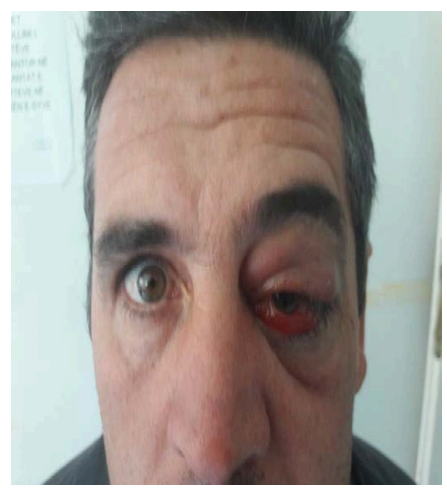

Figure 2. Patient after the admitting in hospital.

Initially, because of the preseptal and orbital cellulitis, he was treated with systemic antibiotics (Cephazolin $1 \mathrm{~g}$ and Gentamycin $120 \mathrm{mg}$ ), local antibiotic eye drops and fat and corticosteroids Dexason (80 mg 1x, i.v.).

Laboratory test revealed SE $=12$ in first hour and 15 in second, WHC $=6.3$ $10^{3} / \mathrm{mm}^{3}, \mathrm{RBC}=5.3610^{3} / \mathrm{mm}^{3}, \mathrm{PLT}=18410^{3} / \mathrm{mm}^{3}, \mathrm{LYM}=21.9 \%, \mathrm{MON}=$ $6.1 \%$, GRA $=72 \%$, Glucosa OX $=4.21 \mathrm{mmol} / \mathrm{l}$, Urea $7.31 \mathrm{mmol} / \mathrm{l}$, Creatinine $101.1 \mathrm{mmol} / \mathrm{l}$ and CRP-HL $=0.0 \mathrm{mg} /$; all in normal ranges.

RTG pulmo had no significant changes. Cranio-orbital MRI revealed no intracranial involvement with suspicion of preseptal/orbital cellulitis and differential diagnosis for pseudotumor or lymphoma (Figure 3).

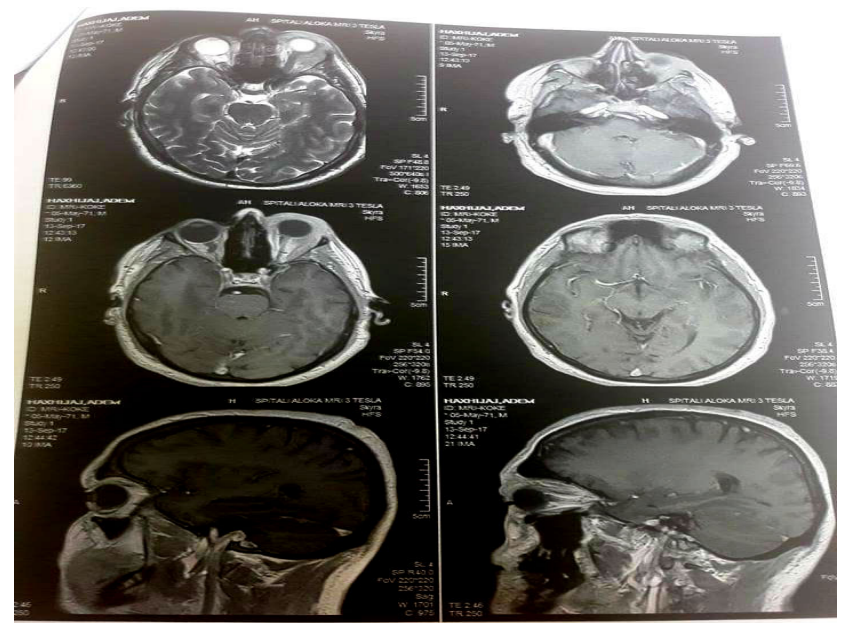

Figure 3. Initial Cranio-orbital MRI. 
We switched the treatment, adding to local antibiotics and corticosteroids; Prednison $(20 \mathrm{mg} 4 \times 1)$, the Bactrim $(480 \mathrm{mg} 2 \times 2$ ). Although the visual acuity was still normal, the motility movement started to limit with no pupillary reaction and progression of the symptoms. We returned previous treatment and recommended to the patient the biopsy, which he refused.

In 2 days visual acuity still remained normal, but the intraorbital tension was TOD $=13.0 \mathrm{mmHg}$ and $\mathrm{TOS}=48.0 \mathrm{mmHg}$, which we treated with Diamox $(2 \times$ 2 ) and Tymolol $0.5 \%(2 \times 2)$, but will with no recovery (Figure 4$)$.

In meanwhile, the proptosis advanced with dislocation down and nasal, with no motility movement, no pupillary reaction, cornea exposal and amaurotic eye (Figure 5). Second cranio-orbital MRI revealed still no intracranial involvement, but morbid progression of the diseases (Figure 6).

The biopsy was performed and the results revealed neoplastic-lymphoid non-Hodgkin lymphoma. The full body CT was made with result of mediastinal and hillar limphadenopathy.

After the immunohistochemical analysis the definitive diagnosis revealed neoplastic-lymphoid non-Hodgkin lymphoma, "high grade" diffuse large B-cell lymphoma. The patient was transferred in the Hematology department for the further treatment.

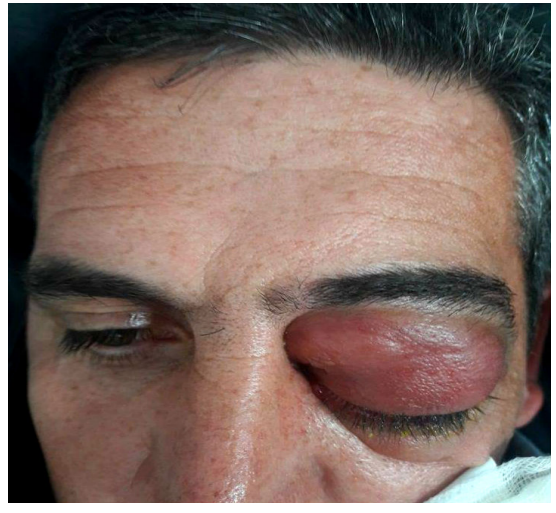

Figure 4. Progression of the disease.

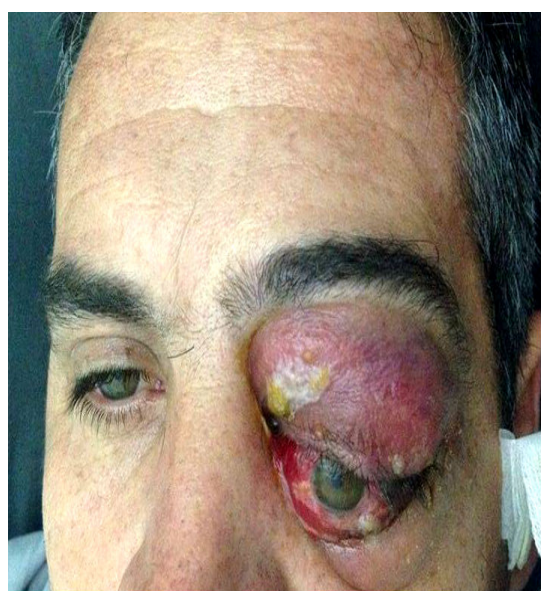

Figure 5. Progression of the symptoms. 


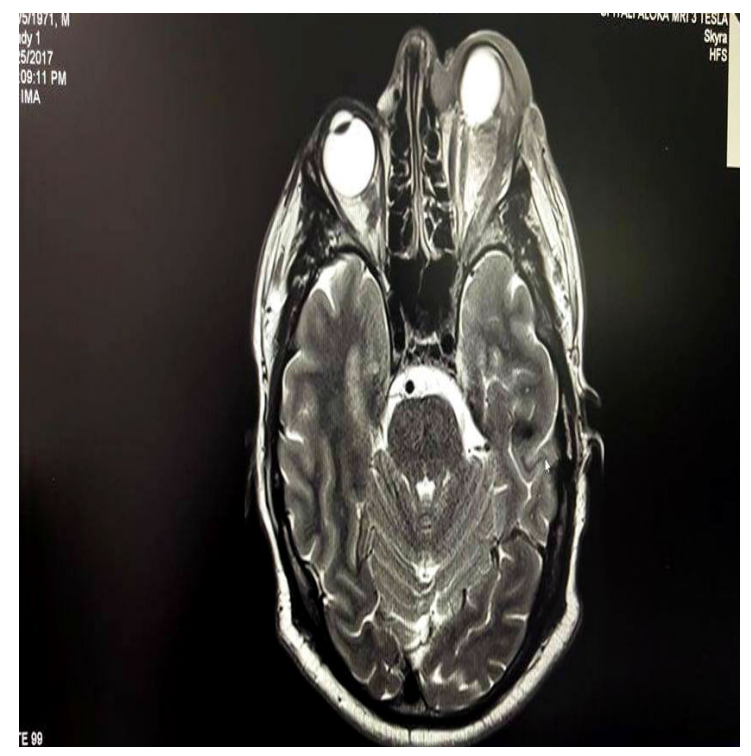

Figure 6. Second Cranio-orbital MRI.

\section{Discussion}

Primary orbital adnexal lymphoma is a rare disease. It involves eyelid, orbital lacrimal glands or conjunctivae. Non-Hodgkin lymphoma is a heterogeneous group of malignant lymphoma reflecting development stage of lymphocytes majority arising from B-cell origin [8]. Owning unspecific clinical sign often causes delay in diagnosis, because of differential diagnosis with inflammatory orbital diseases and pseudotumors.

Our patient, because of the initial sign's and symptoms was treated as preseptal and than orbital cellulitis, starting with antibiotics and corticosteroids. Additional to the treatment, laboratory test and Imaging investigation, as work up at diagnosing OAL [13], revealed initially suspicious of the presetal/orbital cellulitis.

The very fast progression of the diseases, from eyelid to lacrimal glands, at one point "S like proptosis" and posterior orbita more like IOD sympthoms [11], made the diagnosis ever harder.

Analyzing all the possible predisposing factors, there were no viral infections, immunosuppressive treatment, environmental factors or any other systemic involvement that could lead the present of other extranodal lymphomas [5] or other systemic diseases.

Although the duration of the symptoms at the presentation range can variety from 10 day with mean duration of 18 months [14], our patient refusing the biopsy, went from normal visual acuity to amaurotic eye in just few days.

The age manifestation was not typical for our patient. Knowing that the "high grade" aggressive type of orbital adnexal non-Hodgkin lymphomas, DLBCL and MCL represent $15 \%-20 \%$ of lymphomas, where DLBCL is most common subtype with male predominance, but with median age 70's [15].

After the DLBCL diagnosis, the cranio-ocular CT revealed no cranial in- 
volvement, but full-body CT revealed mediastial-hillar limphadenopathy. Comparing to initial examination with no body spreading, questioning thought the diagnostic delay and prognostic outcome.

\section{Conclusion}

Orbital adnexal DLBCL is very aggressive lymphoma. According to the guidelines for the diffuse large B-cell lymphoma, excision surgery or incision biopsy is recommended. However, unspecific symptoms, unusual age for the disease, absence of the predisposing factors and unrevealing laboratory results mask the diseases with other DD diseases, confusing and delaying the diagnosis. The timing from representing symptoms and diagnosing can have huge impact on prognostic outcome for the patient. Therefore, because of the suspicion of presence of malignant lymphoma, we would like to emphasize the importance of exhaustive initial examination; especially even earlier biopsy, in patients with IOD or pseudotumors not reacting to the treatment.

\section{Conflict of Interest}

Authors declare no conflict of interest.

\section{Author Contributions}

Blerta Rama-Substantial contributions to conception and design, Acquisition of data, Analysis and interpretation of data, Drafting the article, Revising it critically for important intellectual content, Final approval of the version to be published; Anita Syla Lokaj-Analysis and interpretation of data, Revising it critically for important intellectual content, Final approval of the version to be published; Egzona Agusholli-Final approval of the version to be published.

\section{References}

[1] Swerdlow, S.H., Zukerberg, L.R., Yang, W.I., Harris, N.L. and Williams, M.E. (1996) The Morphologic Spectrum of Non-Hodgkin's Lymphomas with BCL1/Cyclin D1 Gene Rearrangements. American Journal of Surgical Pathology, 20, 627-640. https://doi.org/10.1097/00000478-199605000-00009

[2] Wayback Machine. 2014. https://web.archive.org/web/20140714194242/http://www.lls.org/content/nationalco ntent/resourcecenter/freeeducationmaterials/lymphoma/pdf/lymphomaguide.pdf

[3] Extranodal Lymphomas. http://www.lymphomation.org/type-extranodal.htm

[4] Zucca, E., Roggero, E., Bertoni, F., Conconi, A. and Cavalli, F. (1999) Primary Extranodal Non-Hodgkin's Lymphomas. Part 2: Head and Neck, Central Nervous System and Other Less Common Sites. Annals of Oncology, 10, 1023-1033. https://doi.org/10.1023/A:1008313229892

[5] Zucca, E., Roggero, E., Bertoni, F. and Cavalli, F. (1997) Primary Extranodal Non-Hodgkin's Lymphomas. Part 1: Gastrointestinal, Cutaneous and Genitourinary Lymphomas. Annals of Oncology, 8, 727-737. https://doi.org/10.1023/A:1008282818705

[6] Margo, C.E. and Mulla, Z.D. (1998) Malignant Tumors of the Orbit. Analysis of the 
Florida Cancer Registry. Ophthalmology, 105, 185-190.

[7] Chan, C.-C. and Wallace, D.J. (2004) Intraocular Lymphoma: Update on Diagnosis and Management. Cancer Control Journal, 11, 285-295.

https://doi.org/10.1177/107327480401100502

[8] Lamba, N., Dworak, D.P., Patel, S.A. and Chennuri, R. (2016) A Case Report of Primary Orbital Non-Hodgkin's Lymphoma Causing Complete Vision Loss. GMS Ophthalmol Cases, 6, Doc06.

http://www.ncbi.nlm.nih.gov/pmc/articles/PMC5015789/

[9] Kakkassery, V., Stübiger, N., Adamietz, I.A., Tischoff, I., Baraniskin, A. and Wunderlich, I.M. (2015) [Lymphoma of the Ocular Adnexa.] Der Ophthalmologe: Zeitschrift Der Deutschen Ophthalmologischen Gesellschaft, 112, 210-216.

[10] Watkins, L.M., Carter, K.D. and Nerad, J.A. (2011) Ocular Adnexal Lymphoma of the Extraocular Muscles: Case Series from the University of Iowa and Review of the Literature. Ophthalmic Plastic \& Reconstructive Surgery, 27, 471-476. https://doi.org/10.1097/IOP.0b013e31822e5c1b

[11] Pakdaman, M.N., Sepahdari, A.R. and Elkhamary, S.M. (2014) Orbital Inflammatory Disease: Pictorial Review and Differential Diagnosis. World Journal of Radiology, 6, 106-115. https://doi.org/10.4329/wjr.v6.i4.106

[12] Tőrők-Vistai, T., Bojan, A., Cucuianu, A. and Zsoldos, A. (2013) Primary Non-Hodgkin Lymphoma of the Orbit Presenting with Massive Bilateral Periorbital Tumors. Clujul Medical, 86, 380-382.

[13] http://www.bloodjournal.org/content/bloodjournal/108/5/1451.full.pdf?sso-checked $=$ true

[14] Tranfa, F., Di Matteo, G., Strianese, D., Forte, R. and Bonavolontà, G. (2001) Primary Orbital Lymphoma. Orbit (Amsterdam, Netherlands), 20, 119-124. https://doi.org/10.1076/orbi.20.2.119.2633

[15] Morton, L.M., Wang, S.S., Devesa, S.S., Hartge, P., Weisenburger, D.D. and Linet, M.S. (2006) Lymphoma Incidence Patterns by WHO Subtype in the United States, 1992-2001. Blood, 107, 265-276. https://doi.org/10.1182/blood-2005-06-2508 